\title{
Adjuvant oestrogen therapy does not improve disease activity in postmenopausal patients with rheumatoid arthritis
}

\author{
H R van den Brink, A A van Everdingen, M J G van Wijk, J W G Jacobs, J W J Bijlsma
}

\begin{abstract}
Objective To investigate whether oestrogens can be used as treatment to diminish disease activity in women with rheumatoid arthritis.

Methods-Forty postmenopausal female patients with active rheumatoid arthritis participated in a placebo-controlled, double-blind study on the possible beneficial effect of adjuvant treatment of oestradiol on disease activity.

Results-Thirty three patients completed 52 weeks of treatment with $2 \mathrm{mg}$ oestradiolvalerate or placebo. No statistically significant difference was found in and between both treatment groups with regard to articular indices, pain score by visual analogue scale, erythrocyte sedimentation rate and health questionnaire on daily activities before, during and at the end of the study.

Conclusion-This first randomised prospective placebo-controlled study shows no beneficial effect of oestrogens on disease activity in postmenopausal female patients with rheumatoid arthritis.
\end{abstract}

(Ann Rheum Dis 1993; 52: 862-865)

Epidemiological and immunological data suggest that female hormones may play a role in the aetiology and course of rheumatoid arthritis (RA). There is a clear female to male preponderance of the disease. ${ }^{1}$ In women the use of oral contraceptives may protect against development of RA or reduce the severity of the disease. ${ }^{2}{ }^{3}$ Disease symptoms are generally less in the second half of the menstrual cycle when sex steroid levels are high, ${ }^{4}$ whereas the risk of developing the disease is highest at the age of the menopause. ${ }^{5}$ During pregnancy there is often a decrease in disease activity of $\mathrm{RA}$, with a flare up in the weeks after delivery. ${ }^{6}$ In animal models adjuvant oestrogens have been shown to suppress collagen induced arthritis. ${ }^{7}$ Most circumstantial data until now suggest a beneficial effect of oestrogens on disease activity. ${ }^{8}$

A few small uncontrolled studies have investigated possible therapeutic effects of sex hormones on human disease, with conflicting results. ${ }^{9-11}$ Recently two small studies, with a different design have been reported. One of them reported some, and the other no beneficial effect of oestrogens on disease activity in women with RA. ${ }^{12} 13$ To investigate the possible beneficial effects of oestrogens on disease activity, we conducted a double-blind placebo-controlled study lasting one year in forty postmenopausal female patients with RA.

\section{Patients and methods}

Patients

Forty postmenopausal female patients with adult onset RA were admitted to the study; no contraindication for oestrogen treatment was found in any of the patients. Patients were considered to be postmenopausal when there had been no menstruation in the previous year. Patients using corticosteroids or hormonal replacement therapy were not allowed to participate in the study. All patients fulfilled the reviewed criteria for $\mathrm{RA}^{14}$ and had active disease defined by at least 3 of the following criteria: a) more than 6 painful joints; b) more than 3 swollen joints; c) erythrocyte sedimentation rate $>28 \mathrm{~mm} / 1 \mathrm{~h}$; d) morning stiffness $>45$ minutes. When patients used disease modifying anti-rheumatic drugs (DMARD), these were used in a constant dose for at least three months before the start of the study and the dose of these drugs was kept stable during the study.

\section{Study design}

The trial was a double-blind controlled study comparing the additional effect of $2 \mathrm{mg}$ oestradiolvalerate $\left(\right.$ Progynova $^{R}$ ) and placebo for 52 weeks. Patients were randomly allocated to one of the two treatment groups. Oestradiolvalerate and placebo were provided in indistinguishable capsules. The capsules were taken in cycles of 84 days. The last 10 days of each cycle the patients received $200 \mathrm{mg}$ progesterone $\left(\right.$ Progestan $^{R}$ ) to induce a withdrawal bleeding. To try to maintain the double-blind character of the study and to control for a possible effect of progesterone the patients receiving placebo were also treated with progesterone. After each cycle of 84 days the trial medication was discontinued for 1 week. The complete trial consisted of 4 cycles.

\section{Evaluation}

Clinical and laboratory assessment of disease activity was performed every 2 months. For joint evaluation both the Ritchie articular index and the Thompson articular index were recorded. ${ }^{15-17}$ All joint scores were assessed by the same observer. Pain was recorded on a 100

Professor Bijlsma,

Rheumatology F02.223

University Hospital Utrecht, PO Box 85500,3508 GA
} 
Table 1 Demographic and disease characteristics of 40 patients (start of the study)

\begin{tabular}{|c|c|c|c|}
\hline Characteristic & \multicolumn{2}{|c|}{ Oestrogen group $(n=20)$} & Placebo group $(n=20)$ \\
\hline Age in years (SD) & & $61(5)$ & $63(8)$ \\
\hline ARA functional class (SD) & $\begin{array}{l}\text { I } \\
\text { II } \\
\text { III } \\
\text { IV }\end{array}$ & $\begin{array}{r}1 \\
16 \\
3 \\
0\end{array}$ & $\begin{array}{r}3 \\
15 \\
2 \\
0\end{array}$ \\
\hline Disease duration in years SD) & & $9 \cdot 1(4 \cdot 2)$ & $9 \cdot 0(5 \cdot 7)$ \\
\hline Rheumafactor positive (\%) & & $20(100 \%)$ & $17(85 \%)$ \\
\hline Erosions $(\%)$ & & $19(96 \%)$ & $20(100 \%)$ \\
\hline NSAID use (\%) & & $17(85 \%)$ & $17(85 \%)$ \\
\hline $\begin{array}{l}\text { DMARD use (\%) } \\
\text { anti-malarials } \\
\text { sulphasalazine } \\
\text { gold (oral) } \\
\text { gold (intra-muscular) } \\
\text { methotrexate } \\
\text { none }\end{array}$ & & $\begin{array}{l}17(85 \%) \\
1 \\
9 \\
3 \\
2 \\
2 \\
3\end{array}$ & $\begin{array}{l}17(85 \%) \\
2 \\
8 \\
2 \\
1 \\
4 \\
3\end{array}$ \\
\hline \multicolumn{4}{|l|}{ Disease activity parameters ${ }^{\star}$} \\
\hline Ritchie score (SD) (range 0-76) & & $16 \cdot 1(4 \cdot 8)$ & $16 \cdot 6(6 \cdot 4)$ \\
\hline Thompson score (SD) (range 0-534) & & $170(86)$ & $171(89)$ \\
\hline Pain score VAS (SD) (range 0-100) & & $36(13)$ & $43(12)$ \\
\hline VDF/HAQ (SD) (range 20-80) & & $38(13)$ & $39(11)$ \\
\hline $\mathrm{ESR}(\mathrm{SD})$ & & $37(15)$ & $33(15)$ \\
\hline
\end{tabular}

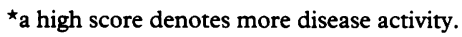

mm horizontal visual analogue scale $(0=$ no pain; 100 = worst pain possible). The following laboratory parameters were measured: erythrocyte sedimentation rate (ESR) and sex hormone binding globulin (SHBG). A standardised questionnaire on daily activities (VDF), a validated Dutch version of the $\mathrm{HAQ}^{18}$ was recorded at the start, after six months and twelve months (range of VDF/ HAQ is $20-80$; a low score denotes a good functional capacity).

\section{Ethics}

The approval of the Medical Ethics Committee of the Unversity Hospital Utrecht was obtained. All patients gave their informed consent.

\section{Statistics}

After performing statistical tests for normal distribution Number Crunches Statistical System), the following statistics were used in analysing the data: paired $t$ tests (within the same treatment group) and two sample $t$ tests (between treatment groups). P values $<0.05$ were considered statistically significant. For 2 variables, that is, the Ritchie and pain score, a power analysis was performed. ${ }^{19}$ The study power was increased by calculating a Pooled Index. ${ }^{20}$ For this Pooled Index the following disease parameters were used: Thompson joint score, pain, VDF/HAQ and ESR. For these parameters the standardised variables were calculated: standard variable $=$ (variable measured - mean)/standard deviation. For all standard variables the sign was adjusted so that positive values indicate improvement for the

Table 2 Sex hormone binding globulin (SD) levels in both treatment groups during the study

\begin{tabular}{llll}
\hline Months & Oestrogen group & Placebo group & p value \\
\hline 0 & $51(14)$ & $56(21)$ & 0.5 \\
6 & $87(34) \dagger$ & $55(23)$ & 0.003 \\
12 & $84(26) \dagger$ & $57(20)$ & 0.002 \\
\hline
\end{tabular}

$\star 2$ sample $t$ test.

tpaired $t$ tests $(\mathrm{p}<0.005)$ patient and negative values indicate that the patient has deteriorated. The pooled index is the arithmetic mean of these 4 standardised variables.

\section{Results}

Patients studied

Forty postmenopausal patients with RA entered the study. Thirty four patients $(85 \%)$ were taking non-steroidal anti-inflammatory drugs (NSAID) and thirty four patients (85\%) used different DMARD. Characteristics of patient groups at the start of the study are shown in table 1. After disclosure of the coding the two groups proved to be comparable for all demographic characteristics and disease activity parameters.

\section{Withdrawals}

Seven of the 40 patients who entered the study withdrew before completing the full 52 weeks. After disclosure of the coding, 5 of the 7 patients were in the oestrogen group and 2 in the placebo group. During the first three months of the trial 3 patients withdrew because of irregular menstrual bleeding, all three patients were in the oestrogen group. The other 4 withdrawals, 2 in the oestrogen and 2 in the placebo group, discontinued between week 26 and 52 because of lack of efficacy. Patients who dropped out from the study were included in the results until withdrawal.

\section{Side effects}

Apart from withdrawal bleeding, no side effects were seen in the patients taking oestradiolvalerate. Most patients ( $70 \%$ ) taking oestrogens had a withdrawal bleeding, while none of the patients taking placebo experienced a withdrawal bleeding.

\section{Compliance}

To check patients' compliance to the study SHBG levels were measured. In all women taking oestrogens SHBG increased considerably. In table 2 mean values are given.

\section{Parameters of disease activity}

The data of the Thompson articular index and ESR of both treatment groups are illustrated in the figure. No significant difference at any assessment during the trial was observed within the treatment regimes for both parameters. Results of changes in all disease activity measurements within each treatment group at the start, after 6 and 12 months are shown in table 3. No statistically significant change of any disease activity parameter was seen after six and twelve months within both treatment groups. Statistical analysis of changes in disease activity parameters between both treatment groups showed no statistically significant differences, except for worsening of the pain in the oestrogen group versus the placebo group (table 4).

Calculations showed that our sample size had a power of $80 \%$ in detecting a difference of 6.9 in Ritchie score and $13.7 \mathrm{~mm}$ in pain score between the two treatment groups. In 


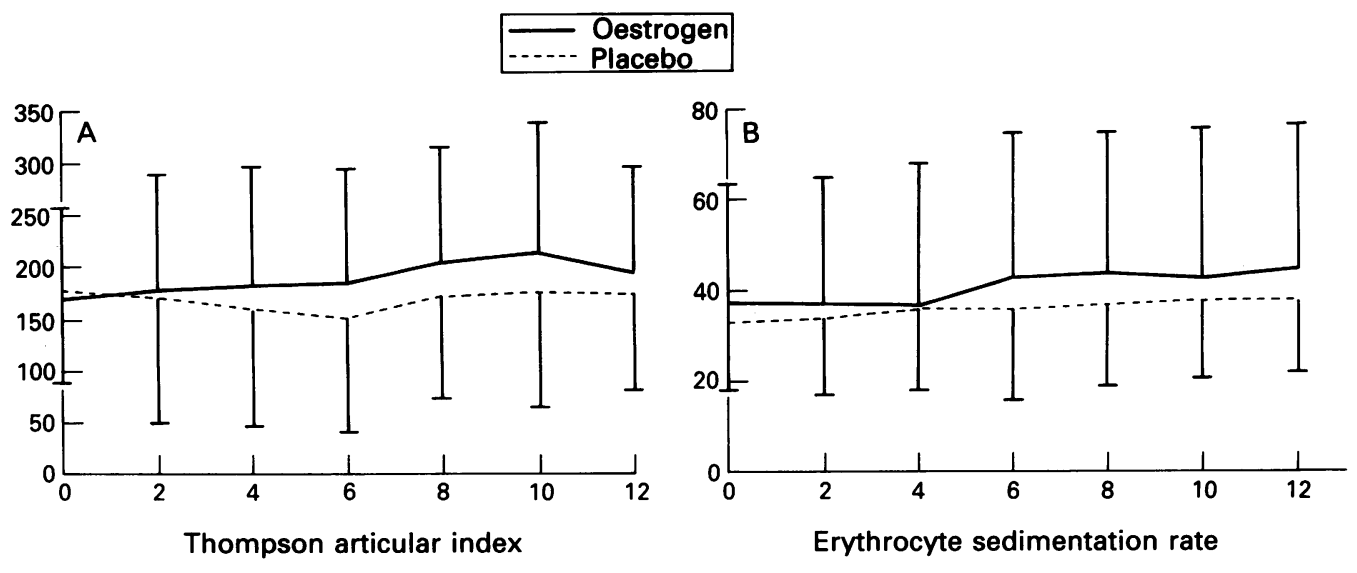

Figure A: The mean Thompson articular index (SD) of both groups during the study year. (Y-axis: Thompson articular index, $X$-axis: time in months); B: The mean ESR (SD) of both groups during the study year. (Y-axis: ESR, $X$-axis: time in months).

Table 3 Changes in disease activity variables from base-line values after 6 and 12 months. Differences within both treatment groups

\begin{tabular}{|c|c|c|c|c|c|c|c|c|c|c|c|c|}
\hline & \multicolumn{6}{|c|}{ Oestrogen group } & \multicolumn{6}{|c|}{ Placebo group } \\
\hline & \multicolumn{3}{|c|}{6 months $(n=17)$} & \multicolumn{3}{|c|}{12 months $(n=15)$} & \multicolumn{3}{|c|}{6 months $(n=20)$} & \multicolumn{3}{|c|}{12 months $(n=18)$} \\
\hline & Mean & $95(\%) C I$ & $p$ value & Mean & $95(\%) C I$ & $p$ value & Mean & $95(\%) C I$ & $p$ value & Mean & $95(\%) C I$ & $p$ value \\
\hline Ritchie score & $0 \cdot 1$ & $-3 \cdot 7$ to 4.0 & 0.9 & $-0 \cdot 3$ & $-4 \cdot 2$ to $3 \cdot 7$ & 0.9 & -0.8 & -5.5 to 4.0 & $0 \cdot 7$ & $-1 \cdot 3$ & $-5 \cdot 2$ to $2 \cdot 5$ & 0.9 \\
\hline Thompson score & 9 & -60 to 77 & 0.8 & 17 & -40 to 70 & 0.5 & -25 & -68 to 19 & $0 \cdot 2$ & $-3 \cdot 3$ & -50 to 43 & 0.5 \\
\hline Pain score VAS & 10 & -3 to 22 & $0 \cdot 1$ & 9 & -1 to 19 & 0.07 & 0 & -1 to 1 & 1 & -4 & -11 to 4 & $0 \cdot 3$ \\
\hline VDF/HAQ & 1 & -3 to 5 & 0.5 & 1 & -4 to 6 & 0.6 & -4 & -11 to 3 & $0 \cdot 2$ & -1 & -4 to 6 & $0 \cdot 2$ \\
\hline ESR & 6 & -2 to 14 & $0 \cdot 1$ & 7 & -1 to 16 & $0 \cdot 2$ & 2 & -11 to 6 & $0 \cdot 6$ & $4 \cdot 5$ & $-0 \cdot 2$ to $9 \cdot 3$ & $0 \cdot 4$ \\
\hline
\end{tabular}

${ }^{\star}$ paired $t$ test.

$\mathrm{CI}=$ confidence interval.

Table 4 Changes in disease activity variables from base-line values after 6 and 12 months. Differences between the two treatment groups: oestrogen group $n=17$ at 6 months, $n=15$ at 12 months; placebo group $n=20$ at 6 months, $n=18$ at 12 months

\begin{tabular}{|c|c|c|c|c|c|c|}
\hline & \multicolumn{6}{|c|}{ Oestrogen versus placebo group } \\
\hline & \multicolumn{3}{|c|}{6 months } & \multicolumn{3}{|c|}{12 months } \\
\hline & Mean & $95(\%) C I$ & p value & Mean & $95(\%) C I$ & $p$ value \\
\hline Ritchie score & 0.9 & $-5 \cdot 3$ to $7 \cdot 1$ & 0.76 & 1.5 & $-3 \cdot 8$ to 6.8 & 0.56 \\
\hline Thompson score & 33 & -42 to 108 & 0.37 & 21 & -49 to 92 & 0.54 \\
\hline Pain score VAS & 10 & -6 to 26 & $0 \cdot 20$ & 14 & 3 to 25 & 0.01 \\
\hline $\mathrm{VDF} / \mathrm{HAQ}$ & 2 & -3 to 7 & 0.45 & 3 & -3 to 10 & $0 \cdot 27$ \\
\hline ESR & 4 & -8 to 15 & 0.54 & 5 & -6 to 16 & 0.36 \\
\hline
\end{tabular}

$\mathrm{CI}=$ confidence interval.

table 5 the Pooled Index, using Thompson joint score, pain, VDF/HAQ and ESR is given. No statistically significant changes were observed.

In addition all individual patients were evaluated. When a patient improved $30 \%$ or more on at least 3 disease parameters this patient was considered improved; if there was a deterioration of $30 \%$ or more in at least 3 disease parameters we considered this patient

Table 5 Changes in Pooled Index of disease activity variables from base-line values after 6 and 12 months (a negative value means a deterioration)

\begin{tabular}{lllll}
\hline \multicolumn{1}{l}{$\begin{array}{c}\text { A Differences within both treatment groups } \\
\text { Oestrogens }\end{array}$} & \multicolumn{3}{c}{ Placebo } \\
\cline { 2 - 5 } & 6 months & 12 months & 6 months & 12 months \\
\hline Pooled index & -0.26 & -0.28 (all not significant) & $0 \cdot 05$
\end{tabular}

$B$ Differences between the two treatment groups

\begin{tabular}{lllll} 
& \multicolumn{4}{c}{ oestrogens $\mathrm{v}$ placebo } \\
\cline { 2 - 5 } & 6 months & $p$ & 12 months & $p$ \\
\hline Pooled index & -0.31 & 0.23 (all not significant) & -0.38 \\
\hline
\end{tabular}

to have deteriorated. After 12 months of oestrogen treatment 1 patient was improved, 2 had deteriorated and 12 had no clinically relevant change in disease activity. After 12 months of placebo the figures were: 2 improved, 2 deteriorated, 14 no change. Fisher exact test improved versus deteriorated plus no change, showed that there was no significant difference between both treatment groups.

\section{Discussion}

The influence of female sex hormones on RA has been the subject of investigations in different areas. Most data, both from epidemiological studies in women with RA and from animal models of adjuvant arthritis, suggest a beneficial effect of female sex hormones. ${ }^{21}$ In the 1960 s a few open studies with Enovid $^{\mathrm{R}}$, a progestagen with some oestrogenic properties were undertaken, with conflicting results; two studies reported a favourable effect and in one study no beneficial effect was found. ${ }^{9-11}$ Recently, two different studies investigated the influence of oestrogens upon disease activity of RA. Bijlsma et al performed a pilot trial on the effect of $12,5 \mu \mathrm{g}$ ethinyloestradiol in three premenopausal and seven postmenopausal female patients with $\mathrm{RA}$, in a double-blind crossover study lasting 6 months. All other medication was kept stable during the study. Although the number of patients was small some beneficial effect was detected. ${ }^{12}$ Hazes $e t$ al investigated the effect of Lyndiol $^{\mathrm{R}}$, each tablet containing $2.5 \mathrm{mg}$ lynestrenol and $50 \mu \mathrm{g}$ ethinyloestradiol, on 10 premenopausal patients with moderate active $\mathrm{RA}$ in an open study during six months. ${ }^{13}$ 
Except for the number of swollen and tender joints, no other clinical or laboratory parameter improved. Until now no placebo-controlled studies have been reported on the possible therapeutic effect of oestrogens on disease activity in patients with RA. The technical difficulties of and the need for such an intervention study have been the subject for discussion amongst researchers. ${ }^{21}$ We chose to investigate the effects of oestrogens in postmenopausal patients with RA because the oestrogen levels in peripheral blood are low and if there was to be a beneficial effect from female sex hormones it would be more noticeable in postmenopausal women. In addition there is no menstrual cycle in postmenopausal women which might interfere with the study design or interpretation of the results.

The results of our placebo-controlled study show no beneficial effect of $2 \mathrm{mg}$ oestradiolvalerate on disease activity parameters. In this study only 5 different disease parameters reflecting various important aspects of $R A$ activity were assessed. The use of only a limited number of parameters for assessing disease activity in RA was recently advocated in an article concerning measurements of disease activity in trials. ${ }^{22}$ Also the method of the Pooled Index did not show any beneficial effect of oestradiolvalerate. If there was any trend at all, it showed a deterioration instead of an improvement of disease activity. How reliable and relevant are these negative results?

We do not think that the dose of $2 \mathrm{mg}$ oestradiolvalerate, which is equivalent to $25 \mu \mathrm{g}$ ethinyloestradiol, was too low; this dose is nearly twice as high as that used for perimenopausal complaints and has proved effective in the prevention of postmenopausal bone loss. The use of a higher dose of oestrogen in postmenopausal patients for a prolonged period of time would probably be unethical because of the chance of serious side effects. We do not think that the small dose progesterone given to both groups for 10 days during each 84 day cycle could have had any influence on disease activity.

All patients had sufficient disease activity at the start to detect a change of disease activity if there was really an effect. The study period of one year is long enough to detect beneficial changes in RA activity on this medication.

The wide range of the $95 \%$ confidence intervals in tables 3 and 4 are due to the rather small number of patients studied as well as to the heterogeneity of the patient groups. It is thus possible that a conclusion based only on analysis of the means could be biased by a type II error. However, additional analyses were performed, based on changes in individual patients and on a Pooled Index and these did not show any improvement of disease activity during oestrogen treatment. Undetected possible changes in disease activity are unlikely to be clinically relevant.
In conclusion, no clear beneficial effect of adjuvant therapy with oestradiolvalerate on disease activity in postmenopausal patients with RA was seen in this placebo-controlled double-blind study. Our results show that there is no place for the therapeutic use of adjuvant oestrogens to diminish disease activity of RA. This treatment, however, may improve bone mineral density in these patients. ${ }^{23}$

This work was supported by the Dutch League Against Rheumatism, 'Nationaal Reumafonds'. We thank all the participating patients and Dr Siewertsz van Reesema and Professor te Velde for their help and advice, as well as Schering and Organon for providing the oestrogens and progesteron.

1 Linos A, Worthington J W, O'Fallon W M, Kurland L T. The epidemiology of rheumatoid arthritis in Rochester Minnesota: a study of its incidence, prevalence and mortality. Am f Epidemiol 1980; 111: 87-98.

2 Wingrave S J, Kay C R. Reduction in incidence of rheumatoid arthritis associated with oral contraceptives. rheumatoid arthritis ass

3 Spector T D, Hochberg M C. The protective effect of the oral contraceptive pill: an overview of the analytical epidemiological studies using meta-analysis. $\mathcal{f}$ Clin Epidemiol 1990; 43: 1221-30.

4 Latman N S. Relation of menstrual cycle phase to symptom of rheumatoid arthritis. Am f Med 1983; 74: 957-60.

5 Goemaere S, Ackerman C, Goethals, Keyser F de, et al. Onset of symptoms of rheumatoid arthritis in relation to age, sex and menopausal transition. $\mathcal{F}$ Rheumatol 1990; 17 $1620-2$.

6 Klipple G L, Cecere F A. Rheumatoid arthritis and pregnancy. Rheum Dis Clin N America 1989; 15: 215-39.

7 Holmdahl R, Jansson, Andersson M. Female sex hormones suppress development of collagen-induced arthritis in suppress development of collagen-ind
mice. Arthritis Rheum 1986; 26: 1501-9.

8 Brink H R van den, Bijlsma J W J. Can oestrogens be used as adjuvant therapy in female patients with rheumatoid as adjuvant therapy in female patients with rheum
arthritis? Br $\mathcal{J}$ Rheumatol 198928 (suppl 1): 24-7.

9 Blais J A, Demers. The use of norethynodrel (Enovid) in the treatment of rheumatoid arthritis. Arthritis Rheum 1962; 5: 284

10 Waine H, Frieden E H, Caplan H I, Cole T. Metabolic effects of Enovid in rheumatoid patients. Arthritis Rheum 1963; 6: 796 .

11 Gilbert M, Rotstein J, Pincus G, et al. Norethynodrel with mestranol in treatment of rheumatoid arthritis. $\mathcal{f} A M A$ 1964; 3: 235 .

12 Bijlsma J W J, Huber-Bruning $\mathrm{O}$, Thijssen J H H. Effect of oestrogen treatment on clinical and laboratory manifestations of rheumatoid arthritis. Ann Rheum Dis 1987; 46: 777-9.

13 Hazes J M W, Dijkmans B A C, VandenBroucke J P, Cats A. Oral contraceptive treatment for rheumatoid arthritis: an open study in 10 female patients. Br $\mathcal{F}$ Rheumatol 1989 ; 28 (suppl 1): $28-30$.

14 Arnett F C, Edworthy S M, Bloch D E, et al. The American Rheumatism Association 1987 revised criteria for the classification of rheumatoid arthritis. Arthritis Rheum 1988; 31: 315-24.

15 Ritchie D M, Boyle J A, McInnes J M, et al. Clinical studies with the articular index for the assessment of join tenderness in patients with rheumatoid arthritis. $Q \mathcal{F} M e d$ 1968; 37: 393-406.

16 Thompson P W, Silman A, Kirwan J R, Currey H L F. Articular indices of joint inflammation in rheumatoid arthritis. Arthritis Rheum 1987; 30: 618-23.

17 Brink H R van den, Heide A van der, Jacobs J W G, Veen $M$ J van der, Bijlsma J W J. Evaluation of the Thompson Articular Index. $\mathcal{A}$ Rheumatol 1993; 20: 28-32.

18 Biilsma J W J, Oude Heuvel C H B, Zaalberg A. Development and validation of the Dutch questionnaire capacities of daily life (VDF) for patients with rheumatoid capacities of daily life (VDF) for pati

19 Altman D G. Practical statistics for medical research. London: Chapman and Hall, 1991.

20 Goldsmith $\mathrm{C} \mathrm{H}$, Smythe H A, Helewa A. Interpretation and Power of a Pooled Index. $\mathcal{f}$ Rheumatol 1993; 20: 575-8.

21 Siman A J, Vandenbroucke J P. Female sex hormones and rheumatoid arthritis. Br 7 Rheumatol suppl 1989; 28 $1-75$

22 Heide A van der, Jacobs J W G, Dinant H J, Bijlsma J W J. The impact of endpoint measures in rheumatoid arthritis clinical trials. Sem Arthritis Rheum 1992; 21: 287-94.

23 Brink $H$ R van den, Lems W F, Everdingen A A van, Bijlsma J W J. Adjuvant oestrogen treatment increases bone mineral density in postmenopausal women with rheumatoid arthritis. Ann Rheum Dis 1993; 52: 302-5. 